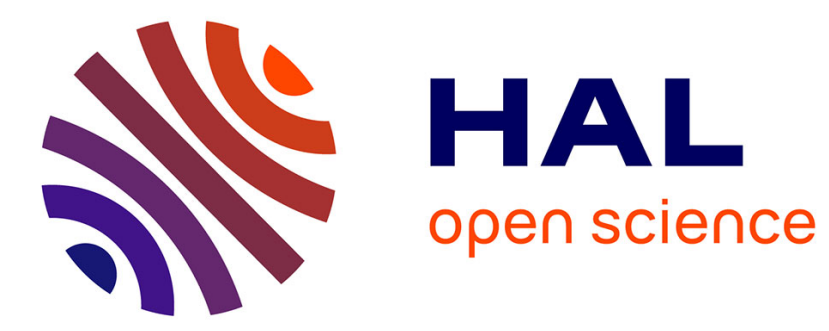

\title{
Inferring Art Preferences from Gaze Exploration in a Museum
}

\author{
Sylvain Castagnos, Florian Marchal, Alexandre Bertrand, Morgane Colle, \\ Djalila Mahmoudi
}

\section{- To cite this version:}

Sylvain Castagnos, Florian Marchal, Alexandre Bertrand, Morgane Colle, Djalila Mahmoudi. Inferring Art Preferences from Gaze Exploration in a Museum. 10th Workshop on Personalized Access to Cultural Heritage (PATCH 2019), Jun 2019, Larnaca, Cyprus. pp.425-430, 10.1145/3314183.3323871. hal-02472007

\section{HAL Id: hal-02472007 https://hal.science/hal-02472007}

Submitted on 15 Oct 2020

HAL is a multi-disciplinary open access archive for the deposit and dissemination of scientific research documents, whether they are published or not. The documents may come from teaching and research institutions in France or abroad, or from public or private research centers.
L'archive ouverte pluridisciplinaire HAL, est destinée au dépôt et à la diffusion de documents scientifiques de niveau recherche, publiés ou non, émanant des établissements d'enseignement et de recherche français ou étrangers, des laboratoires publics ou privés. 


\section{Inferring Art Preferences from Gaze Exploration in a Museum}

\author{
Sylvain Castagnos \\ CNRS - LORIA - Univ. of Lorraine \\ Vandoeuvre, France \\ sylvain.castagnos@loria.fr
}

\author{
Florian Marchal \\ CNRS - LORIA - Univ. of Lorraine \\ Vandoeuvre, France \\ florian.marchal@loria.fr
}

\author{
Alexandre Bertrand \\ IDMC - Univ. of Lorraine \\ Nancy, France \\ alexandre.bertrand5@etu.univ-lorraine.fr
}

\author{
Morgane Colle \\ IDMC - Univ. of Lorraine \\ Nancy, France \\ morgane.colle8@etu.univ-lorraine.fr
}

\author{
Djalila Mahmoudi \\ IDMC - Univ. of Lorraine \\ Nancy, France \\ djalila.mahmoudi2@etu.univ-lorraine.fr
}

\begin{abstract}
This paper is a first step towards identifying the links between the characteristics of gaze behaviour and visitor preferences in a museum. In the long term, the real-time analysis of visitors' gaze should allow a fine estimation of their interest for the different artworks exhibited and should replace the fastidious and timeconsuming elicitation of preferences commonly used in traditional recommender systems. To study these links, we carried out a user study at the Nancy Museum of Fine Arts in the North-East of France. This pilot study involved 13 volunteers who had the opportunity to freely explore the museum and contemplate hundreds of artworks for more than 50 minutes on average in May 2018. We were able to analyze millions of fixation points so as to find correlations between the number of fixation points per painting, the time spent looking at a painting, and whether or not this painting is appreciated. We plan to extend this study to 100 visitors in the coming months.
\end{abstract}

\section{CCS CONCEPTS}

- Human-centered computing $\rightarrow$ User studies; $\bullet$ Information systems $\rightarrow$ Recommender systems.

\section{KEYWORDS}

cultural heritage, implicit user modelling, gaze behaviour, user study

\section{ACM Reference Format:}

Sylvain Castagnos, Florian Marchal, Alexandre Bertrand, Morgane Colle, and Djalila Mahmoudi. 2019. Inferring Art Preferences from Gaze Exploration in a Museum. In 27th Conference on User Modeling, Adaptation and Personalization Adjunct (UMAP'19 Adjunct), Fune 9-12, 2019, Larnaca, Cyprus. ACM, New York, NY, USA, 6 pages. https://doi.org/10.1145/3314183.3323871

\section{INTRODUCTION}

Museums are places of art and culture. Very diverse, they are present all over the world, whether in small towns or in capitals, and brew

Permission to make digital or hard copies of all or part of this work for personal or classroom use is granted without fee provided that copies are not made or distributed for profit or commercial advantage and that copies bear this notice and the full citation on the first page. Copyrights for components of this work owned by others than ACM must be honored. Abstracting with credit is permitted. To copy otherwise, or republish, to post on servers or to redistribute to lists, requires prior specific permission and/or a fee. Request permissions from permissions@acm.org.

UMAP'19 Adjunct, June 9-12, 2019, Larnaca, Cyprus

(C) 2019 Association for Computing Machinery.

ACM ISBN 978-1-4503-6711-0/19/06 . \$ \$15.00

https://doi.org/10.1145/3314183.3323871 an audience with very broad horizons, from the art expert to the curious tourist. To attract visitors, museums must reinvent themselves, propose new services, and take advantage of the digital revolution to transform the visitor experience. Museum guides open the way to more interactivity, more content, and allow visitors' paths to be personalized thank to recommender systems.

In this context, the goal of recommender systems is to maximize visitor satisfaction by ensuring, for example, that they do not miss works that may interest them [16], surprise them or experience positive emotions whatever their level of knowledge in art [18], that they learn something [9] and/or that they engage a reflection around a theme [8]. In order to achieve these goals, a recommender system must build a reliable profile of the active user. However, collecting visitors' museum preferences is a very difficult task. Cultural heritage suffers far more from cold start than other application domains like VOD, online music services or e-commerce. Indeed, visitors often come only once to the museum, meaning that the user modelling process has to be achieved in a single session. To initialize the profiles, it is possible to ask the visitors to choose exhibits that they like in the catalog before the visit, in the same way they choose a small panel of TV shows or films when they connect for the first time to a service like Netflix. ${ }^{1}$ Nevertheless, it is difficult for visitors to form an opinion on exhibits from thumbnails, as the feeling is not the same. In addition, visiting time should be primarily spent exploring the museum, rather than making the preferences explicit in a mobile application.

Recently, within the frame of the European project H2020 Cross$\mathrm{Cult}^{2}$, we have proposed a recommender system based on visitors' behaviours in museums [17]. These recommendations in a museum context presuppose to have the location of visitors to whom they address. By observing the way they behave in the museum, we aim at inferring their implicit preferences and characteristics on-the-fly during their visit. We argue that this is a good way to support $\mathrm{CH}$ exploration for first-time and anonymous visitors, by recommending them a personalized route that is dynamically recomputed periodically according to where they go, what they see and how they behave. We can for example hypothesize that the time spent looking at a specific painting may reveal an interest for this painting. This hypothesis has to be validated so as to confirm the relevance of a recommender system based on visitor behaviour. In order to do so, we designed a user study in the museum of fine

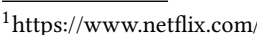

${ }^{2}$ https://www.crosscult.eu/
} 
arts of $\mathrm{Nancy}^{3}$ in which visitors are free to explore the museum while wearing eye-tracking glasses and to provide their preferences regarding the exhibits of the museum at the end of the visit. Our goal is then to see if we can find correlations between some gaze data and the expressed preferences. Such correlations would tend to prove that it is possible to use exploratory and gaze behaviour to infer visitor preferences and adapt recommendations accordingly. We conducted a pilot study with 13 participants and we will discuss the results in this paper.

The rest of this paper is organized as follows: Section 2 will present the state-of-the-art as regards the analysis of visitors' behaviour in museums. Section 3 will introduce our research hypothesis. Section 4 will describe our experiment protocol. Section 5 will summarize the results of our user study. Finally we will conclude the paper and present our perspectives.

\section{RELATED WORK}

Museum institutions have the desire to know their audience. Indeed, the large number of surveys carried out by questionnaire testifies to this $[3,4]$. These surveys aim to gather on-site information about their visitors such as gender, age, educational level, family status, the means of transportation to the museum, the intention to visit, the duration of the visit, the cost or the motivations. There are also national surveys. In France, for example, the Ministry of Culture publishes each year a report entitled Patriostat on museum attendance [5]. All these reports allow to know if a collection or a temporary exhibition was successful, and at the same time, to know the public for each collection or more widely for each type of museum - Fine Arts, Contemporary Art, Archeology, Military, etc.

In parallel, some studies aim at determining the visitors' profile - socio-professional category, personal characteristics - and their behaviours, which can be studied for example via architectural or ethnographic approaches.

The architectural approach, also called spatial syntax, is a field of research initiated in the 1980s by Hillier and Hanson. The purpose of their work was to highlight the link between the architecture of the place and the activity of people, alone or in groups, whether they are living or visiting the place. The basic idea is that architectural variables have a social dimension. Thus, according to this paradigm, architecture prefigures behaviour, influences and conditions social relations. Among the 3 interesting variables from this area of research, the permeability determines, for a given space, the ability of an individual to move from one room to another. The permeability will be high if a large number of doors or transitional spaces - corridors, lifts - allow free movement. Another important notion in spatial syntax is visibility: what an individual can perceive from a given point in space. Benedikt names this two-dimensional space surface an isovist, and has studied its various properties [13] According to him, isosists affect our judgment of space, and could therefore predict it in a closed architectural space. Finally, the third variable is the sequencing: the classical architectural plans are transformed into undirected related graphs, with the nodes representing the museum rooms and the edges the permeability relationships.

While the architectural approach makes it possible to draw the main behavioural trends of a population, it struggles to explain

\footnotetext{
${ }^{3}$ https://musee-des-beaux-arts.nancy.fr/
}

individual behaviours. Other studies then approach the analysis of visitor behaviour from an ethnographic point of view. Veron and Levasseur carried out a study during which they observed the routes, attitudes and comments of of the visitors [21]. A video recording device was used to track the movements of individuals. After their visit, the visitors were thoroughly interviewed. Course analysis resulted in five categories, which were eventually reduced to four types of visitors (ants, fishes, grasshoppers, and butterflies). The classification was made on the basis of the mode of crossing the space, the distance at which the visitor looks at a work, the order of the visit and the variations of this order. The ants stand at a relatively close distance from the works, scrupulously follow the chronology of the exhibition, read their descriptions and rarely cross the empty spaces. The fishes describe a circular trend trajectory while remaining in the center of the room. They give little time to visit and rarely stop. Grasshoppers make successive leaps punctuated by stops at exhibits that interest them. Finally, butterflies have an unpredictable course, guided by chance or for their attraction to certain exhibits. This topology was made from data collected in a single showroom. Zancarano et al. [23] sought to validate the classification of Veron and Levasseur. To do this, they equipped 143 subjects with a guide device, for the visit of the Torre Aquila museum in Italy. An infrared transmitter and receiver system was used to locate visitors and record their movements. They then used the empirical data they collected - visit time, percentage of exhibits seen, order of the visit - and have managed to categorize them into 4 clusters using two supervised learning techniques: a Recurrent Artificial Neural Network and Kmeans. They then compared the characteristics of the clusters with the Veron and Levasseur categories, which favours the validation of the classification. Subsequently, as a continuation of this study, Kuflik et al. [11] wanted to know if the different types of behaviour could be predicted during the early stages of visits. For this, they collected visitor data to be able to model their behaviour by a vector every two minutes, cumulatively, and tried to predict the type of visitor at early stages of the visit. The results show that the quality of the predictions varies according to the category of visit and the moment at which the prediction is made. The authors show that visitors do not always behave consistently - they may change their style during the visit. However, the prediction of their type of visit at early stages remains possible.

Although the classification of Veron and Levasseur is widely used, it is not the only one. For example, Falk [6], in a study focusing on what visitors remember from their visits and what they remember about them learn, studied transcripts of telephone interviews of 22 subjects who had visited museums in the last six months. From this study, he constructed five categories of visitors, based on what motivates them to come to the museum: the Explorers, motivated by their curiosity; the Facilitators, who see the visits as social experiences, times of sharing with those who accompany them; the Professionals, who want to link their passions to what they see in the museum, to satisfy an objective;the Experience Seekers who see the visit as an essential experience: having been there and having seen something; and finally the Rechargers, who see the museum as a refuge and seek to live a restorative, even spiritual and contemplative experience. We see here, with these two classifications, that museum visitors can be characterized in 
several ways: as Veron and Levasseur by the way they move around the museum, as Falk by the search for the motivations of the visits.

In summary, both architectural and ethnographic approaches allow us to analyze the exploratory behaviour of visitors and the associated flows. Nevertheless, they struggle to determine precisely what attracts attention and arouses the interest of visitors. Very recently, Kuflik [10] proposed a research agenda in which mobile eye-trackers should be used as offline as well as online educational aid in art appreciation, since the technology is now mature enough. Eye-tracking systems have been used in museums since the 2000s. For example, Wooding et al. [22] installed a fixed and autonomous eye-tracking device. A visitor sits down, and the eye-tracker is automatically calibrated. Then the visitor views a succession of exhibits on the screen in front of him. The AOIs are then highlighted and studied. More than 5000 subjects participated in this study over nearly three months. However, this experiment was not in the natural situation of a museum visit.

At the Indianapolis Museum of Art, a study was conducted to evaluate the applications of oculometry in museums [20]. The objective was to know if it was possible to obtain an accurate measure of the time spent in front of an exhibit and the points of view of people who stop in front of the work without having to calibrate the eye-tracker. Due to the characteristics of infra-red emitters, the area in which the person was to be placed was quite small, and he or she had to sit down, which makes it difficult to study the ecological conditions of the visit. The evaluation was therefore conducted for a single table, and once the data were collected and analyzed, the authors concluded that their system was not adequate.

Milekic conducted a study in which an eye-tracker is positioned above an artwork [14]. Once the visitor is positioned in front of what he calls the viewing station, the viewpoints are detected, and audio information is delivered based on the elements being viewed. Mokatren et al. [15] proposed a similar system in which a mobile eye-tracker identifies objects of interest, and delivers multimedia content to museum visitors.

The advantages of using an eye-tracker in a museum context are numerous: it makes it possible to investigate the behaviour of visitors without any conscious contribution on their part, without them having to verbalize what they do, or even to access behaviours that they would not be able to explain, or that they do not even have conscience to perform. It also provides access to memory, attention and other cognitive functions of the subjects. With the arrival of more mature technologies, the uses of eye-trackers in museums have diversified and is becoming more widespread, thanks to the reduction in material costs and to its easier and easier handling. In [2], Cantoni et al. rely on an eye-tracker to enhance the user experience through a museum guide. Gaze allows users to select artworks, perform image scrolling, change the size of displayed pictures, define sensitive areas, and generate static images showing a summary of what visitors watched. In the same year, Felicio et al. [7] proposed to integer gaze data in recommender systems. Their algorithm computes visual perception's similarities among users to build a visual perception network of exhibits. Then, this networked information is provided to recommender system to generate recommendations. In [12], the authors suggest using eye-trackers for indoor positioning. Finally, some recent works $[1,19]$ use the eyetracking technology as a reminiscence tool after the visit to explain the visitors' decision making process and motivations, or to analyze their emotions.

Through our user study, we propose a novel way to take advantage of eye-trackers. We aim at inferring visitors' preferences from gaze data.

\section{HYPOTHESIS}

Our hypothesis is the following: "The gaze data differ according to whether the artwork being viewed is appreciated or not". Visitors look differently at an artwork they appreciate and an artwork they do not appreciate. For the definition of appreciation, we mean that a visitor appreciated an exhibit if he/she likes it, if it appeals to him/her, if it arouses his/her interest and/or are relevant according to his/her visit objectives. We assume that visitors not only spend time looking at artworks they are interested in, and not always skip or shorten time next to items they do not like. Time spent next to a painting can be explained in many different ways: trying to understand the scene depicted on the painting, accompanying someone who is interested by the painting, being physically or mentally tired and having a loss of attention... For this reason, we need to analyze gaze data rather than just measuring time spent close to each exhibit. From this assumption ensues the following sub-assumption: "The collected gaze data can infer what visitors have appreciated". In other words, for a given artwork, by studying how the subject looked at it, we should be able to predict whether he/she likes it or not. Thus, gaze data can be classified into two categories: those associated with appreciated artworks, and the others. We suppose that the gaze data linked to appreciated artworks share common characteristics that distinguish them from the works not appreciated, and vice versa.

\section{EXPERIMENT SETUP}

\subsection{Environment}

We did our study at the Nancy Museum of Fine Arts. This museum includes nearly 400 works exhibited to the public and distributed in chronological order over 3 floors. The second floor is devoted to painting from the fourteenth to the sixteenth century, the first floor to painting from the seventeenth to the eighteenth century, and the ground floor is dedicated to the nineteenth and twentieth centuries. If the course on the floors is rather linear leaving visitors to pass from room to room, the ground floor is a much more open space and offers more freedom to visitors (see Figure 1). For this reason, we focused our study on the exploration of the ground floor. This space contains 117 paintings.

\subsection{Material}

For this experiment, we used the eye-tracker Tobii Pro Glasses 2, whose sampling frequency is $100 \mathrm{~Hz}$. We recorded the data with the Tobii Pro Glasses Controller software and analyzed it with the Tobii Pro Lab software version 1.64.6879 on a computer Dell Precision 7720 running Windows 10.

\subsection{Experiment Procedure}

First and foremost, the subject signs an informed consent form that informs him or her of the purpose and conduct of the study, 


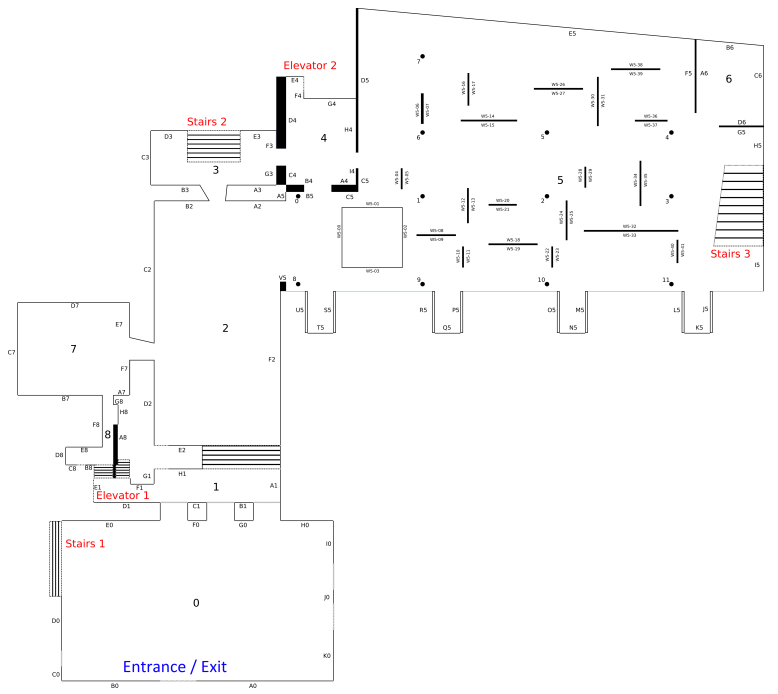

Figure 1: Ground floor of the Nancy museum of fine arts.

as well as the rights regarding his or her data. A declaration to the CIL register has been made to ensure that the data comply with the legal framework. He is then equipped with eye-tracking glasses, which are calibrated, and instructed to visit the museum as naturally as possible, as if he was not wearing the glasses. During the visit, the experimenter has access to the video filmed live by the eye-tracker's scene camera, and can thus quickly intervene in case of a problem. The subject can take as much time as he wants to visit. When the subject has finished his visit, he is invited to answer an online questionnaire on his museum visiting habits, preferences, and feelings about his visit. He also indicates, on a mosaic of the paintings from the ground floor, which takes the form of an Internet page, those he has appreciated (see Figure 2). In order not to solicit visitors too long, we only ask them to express their preferences in the form of likes (a click on the painting is equivalent to a click on a like button).

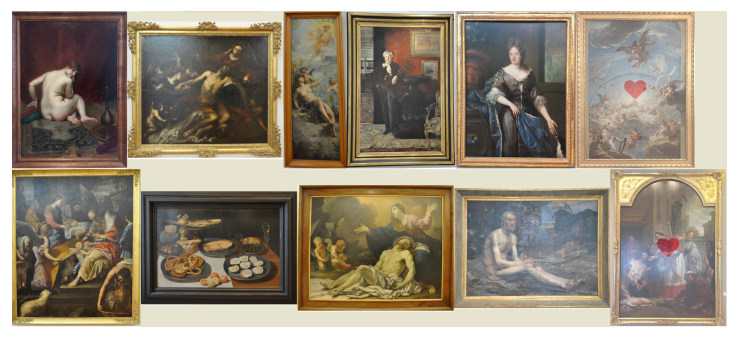

Figure 2: Extract from the mosaic of the paintings from the ground floor.

\subsection{Participants' Background}

A total of 16 subjects participated in the experiment in May 2018: 9 women, 6 men, and one person who did not wish to indicate his/her gender. The vast majority - $81.3 \%$ - were 18 to 24 years old, the others were between 25 and 34 years old. They visit, for the most part, museums a few times a year, or even once or several times a month for a third of the subjects. We collected, with the help of the videos of the scene cameras, for each participant, the duration of their visit, and the time spent on the ground floor (see Figure 3), i.e. the duration of the study strictly speaking since we did not analyze the data collected when the subjects were in the floors. Of the 16 subjects, we only selected 13 visitors who spent time looking at the artworks on the ground floor.

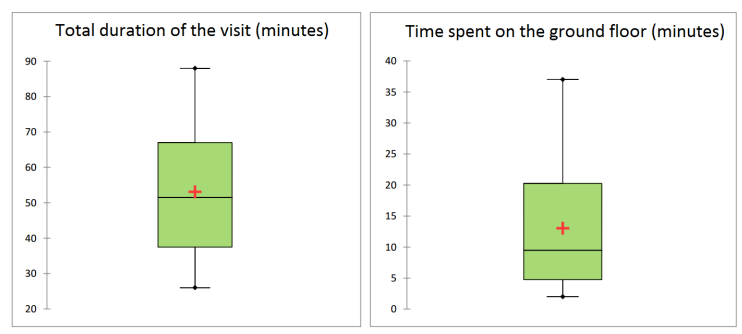

Figure 3: On the left boxplot of the time spent visiting the whole museum and on the right boxplot for the ground floor.

As regards their level of knowledge in art, $12.4 \%$ of participants were art students with a strong knowledge, $43.8 \%$ had a general level, and $43.8 \%$ considered they had a low level.

\section{RESULTS AND DISCUSSION}

Before testing our hypothesis, we analyzed the data collected by the eye-tracker with Tobii Pro Lab software to extract the eye-data from the 117 paintings - of which we had the photos - on the ground floor of the museum. To do this, the software splits the part of the video previously selected into a set of images, then the matching algorithm detects the points of interest on the snapshot (i.e. the desired image, in this case the picture of the painting) and compares with the points of interest of each image in the selection. Point of interest detection is generally done using the contrasts and shapes contained in the images. Once the matching is done, the software's graphical interface allows you to visualize the points of view that match, i.e. those that the software has recognized as being in the snapshot, in other words when the subject looks at the painting. We had to process the 117 paintings for each participant, one after the other, which is extremely time-consuming.

We looked at two variables that we considered relevant for data discrimination, that is to say the distinction between artworks that the visitor likes and the others: the number of fixation points on the painting and the time spent looking at the painting. The goal was to determine if these gaze data differ significantly when a visitor looks a painting he appreciates. We consider that a painting is appreciated by our visitor if it was chosen in the mosaic at the end of the visit. The subjects on average said they enjoyed 11.14 tables on the ground floor.

\subsection{Number of fixation points per painting}

Tobii Pro Lab allowed us to retrieve the gaze data for each painting and each participant, in the form of a csv file containing the pixel coordinates of the fixation points every $10 \mathrm{~ms}$. We then recovered 
the number of distinct fixation points for a given painting and visitor, and repeated this operation on all 117 paintings and 13 visitors. We then carried out statistical tests on these data.

We have chosen to carry out statistical tests from two angles: local tests taking into account the data of only one participant at a time, in order to determine the relevance of the "fixation point" variable for a particular participant, and a global test, including the data of all participants to be able to observe if there is a general trend to produce more fixation points when we appreciate an artwork: this would confirm the significance of the difference in the number of fixation points between artworks that are appreciated and those that are not, despite the fact that visitors do not necessarily have the same gaze behaviours.

We started with local tests: we divided the gaze data of each visitor into two groups: a group containing the number of fixation points of the paintings that the visitor has seen and appreciated, and another containing the number of fixation points of the paintings that the visitor has seen, but of which he did not mention his appreciation in the mosaic: in both groups, we did not take into account the paintings that had no fixation points, so were not seen

The null hypothesis $\mathrm{H} 0$ of the statistical test was that there is no significant difference between the distribution of the data of the two groups, i.e. the number of fixation points does not allow the appreciated paintings to be distinguished from the other paintings. In order to test this hypothesis, we previously used a normality test on the data groups - 2 groups for each participant, i. e. 26 groups, and concluded that for all participants, the groups of appreciated artworks followed a normal distribution, unlike the groups of other artworks for which only two followed a normal law.

We were then able to test $\mathrm{H} 0$. We had two independent samples - the two groups. For each visitor, if the data - those of the two groups - followed a normal distribution, we performed a Student test, parametric, and a Wilcoxon-Mann-Whitney test.

We observe very mixed results: out of 13 participants, 6 have a number of fixations that differ significantly when they look at an artwork they like and one they do not like. For the other 7 participants, this difference is not significant (see Figure 4).

For the global test, we grouped all visitor data into 2 groups: number of fixation points for artworks seen and appreciated on the one hand, and number of fixation points for artworks seen but not mentioned in the mosaic on the other hand. Shapiro's normality tests showed that the two groups did not followed a normal distribution, so we performed a Wilcoxon test and obtained a $p-$ value $=3.857 * 10^{-} 11$. There is thus a significant difference between the data of the two groups. Thus, although the results of local tests do not provide a reliable answer to the hypothesis, the global test confirms that the fixation points can be considered as a variable discriminating in the appreciation of artworks.

\subsection{Time spent looking at the paintings}

Tobii Pro Lab does not give direct access to the viewing time of a snapshot, so we retrieved this data by counting the number of fixation points, including repetitions, and multiplying this number by 10 (time stamp interval) to obtain times in milliseconds. We then carried out local tests and a global test on the same principle as before.

\begin{tabular}{|c|c|c|c|c|}
\hline 1111111111 & Shapiro (Group «A») & \begin{tabular}{|l|l}
$\begin{array}{l}\text { Shapiro-Wilk } \\
\text { «NA } »)\end{array}$ & (Group \\
\end{tabular} & Statistical test & $\begin{array}{l}\text { p- } \\
\text { value }\end{array}$ \\
\hline \multirow[t]{2}{*}{ Participant 1} & \multirow{2}{*}{ Size $<3$} & 0.016 & \multirow{2}{*}{$\begin{array}{l}\text { Wilcoxon-Mann- } \\
\text { Whitney }\end{array}$} & \multirow[b]{2}{*}{0.173} \\
\hline & & Hermaledistribution & & \\
\hline \multirow[t]{2}{*}{ Participant 2} & 0.6368 & $2.19 * 10^{\wedge}-7$ & \multirow{2}{*}{\begin{tabular}{|l}
$\begin{array}{l}\text { Wilcoxon-Mann- } \\
\text { Whitney }\end{array}$ \\
\end{tabular}} & \multirow[b]{2}{*}{0.0046} \\
\hline & Normal distribution & Nermaledistribution & & \\
\hline \multirow[t]{2}{*}{ Participant 3} & & & \multirow[b]{2}{*}{ T-Student } & \multirow[b]{2}{*}{0.82} \\
\hline & Size $<3$ & Size $<3$ & & \\
\hline \multirow[t]{2}{*}{ Participant 4} & 0.45 & 0.0049 & \multirow{2}{*}{$\begin{array}{l}\text { Wilcoxon-Mann- } \\
\text { Whitney }\end{array}$} & \multirow[b]{2}{*}{0.0073} \\
\hline & Normal distribution & Hormaletistribution & & \\
\hline \multirow[t]{2}{*}{ Participant 5} & 0.07 & 0.00019 & \multirow{2}{*}{$\begin{array}{l}\text { Wilcoxon-Mann- } \\
\text { Whitney } \\
\end{array}$} & \multirow[b]{2}{*}{0.0397} \\
\hline & Normal distribution & Hermal distribution & & \\
\hline \multirow[t]{2}{*}{ Participant 6} & 0.1218 & 0.0146 & \multirow{2}{*}{$\begin{array}{l}\text { Wilcoxon-Mann- } \\
\text { Whitney }\end{array}$} & \multirow[b]{2}{*}{0.054} \\
\hline & Normal distribution & Hormaletistribution & & \\
\hline \multirow[t]{2}{*}{ Participant 7} & 0.092 & 0.009 & \multirow{2}{*}{$\begin{array}{l}\text { Wilcoxon-Mann- } \\
\text { Whitney }\end{array}$} & \multirow[b]{2}{*}{0.042} \\
\hline & Normal distribution & Hormatelistribution & & \\
\hline \multirow[t]{2}{*}{ Participant 8} & 0.7804 & 0.234 & \multirow[b]{2}{*}{ T-Student } & \multirow[b]{2}{*}{0.32} \\
\hline & Normal distribution & Normal distribution & & \\
\hline \multirow[t]{2}{*}{$\begin{array}{l}\text { Participant } \\
9\end{array}$} & 0.0045 & 0.0011 & \multirow{2}{*}{$\begin{array}{l}\text { Wilcoxon-Mann- } \\
\text { Whitney } \\
\end{array}$} & \multirow[b]{2}{*}{0.2849} \\
\hline & Normal distribution & Normal distribution & & \\
\hline \multirow[t]{2}{*}{$\begin{array}{l}\text { Participant } \\
10\end{array}$} & & 9,577 & \multirow{2}{*}{$\begin{array}{l}\text { Wilcoxon-Mann- } \\
\text { Whitney }\end{array}$} & \multirow[b]{2}{*}{0.1049} \\
\hline & Size $<3$ & Hermatelistribution & & \\
\hline \multirow{2}{*}{$\begin{array}{l}\text { Participant } \\
11\end{array}$} & 0.0088 & $1.1718^{\star} 10^{\wedge}-5$ & \multirow{2}{*}{$\begin{array}{l}\text { Wilcoxon-Mann- } \\
\text { Whitney }\end{array}$} & \\
\hline & Hormal distribution & Hermal elistribution & & 0.0988 \\
\hline $\begin{array}{l}\text { Participant } \\
12\end{array}$ & 0.2769 & 0.0460 & & \\
\hline & Normal distribution & Hermal clistribution & $\begin{array}{l}\text { Wilcoxon-Mar } \\
\text { Whitney }\end{array}$ & 0.0026 \\
\hline $\begin{array}{l}\text { Participant } \\
13\end{array}$ & 0.2863 & 0.0070 & & \\
\hline & Normal distribution & Normal distribution & T-Student & 0.019 \\
\hline
\end{tabular}

Figure 4: Analysis of the number of fixation points.

For the local tests, 7 participants have a viewing time that differs significantly when they watch an artwork they appreciate, while the 6 other participants do not show any difference.

The global test shows a significant difference between the data of the two groups (Wilcoxon-Mann-Whitney, $p-$ value $=4.158 *$ $\left.10^{-} 12\right)$. Thus, the conclusion is the same as for fixations: the results of local tests are mixed, and the global test favours the discriminating power of the viewing time for the appreciation of artworks, a result that must be confirmed by a larger amount of data.

\begin{tabular}{|c|c|c|c|c|}
\hline|||||||||||||||||||||| & \begin{tabular}{|l} 
Shapiro-Wilk \\
(Groupe « A »)
\end{tabular} & $\begin{array}{l}\text { Shapiro-Wilk } \\
\text { (Groupe « NA ») }\end{array}$ & Statistical test & p-value \\
\hline \multirow[t]{2}{*}{ Participant 1} & \multirow[b]{2}{*}{ Size $<3$} & 0.02 & \multirow{2}{*}{$\begin{array}{l}\text { Wilcox on-Mann- } \\
\text { Whitney }\end{array}$} & \multirow[b]{2}{*}{0.2222} \\
\hline & & Normal distribution & & \\
\hline \multirow[t]{2}{*}{ Participant 2} & 0.916 & $6.216 * 10^{\wedge}-8$ & \multirow{2}{*}{$\begin{array}{l}\text { Wilcox on-Mann- } \\
\text { Whitney }\end{array}$} & \multirow[b]{2}{*}{0.0060} \\
\hline & Normal distribution & Normal distribution & & \\
\hline \multirow[t]{2}{*}{ Participant 3} & & & \multirow[b]{2}{*}{ T-Student } & \multirow[b]{2}{*}{0.7102} \\
\hline & Size $<3$ & Size $<3$ & & \\
\hline \multirow[t]{2}{*}{ Participant 4} & 0.632 & 0.003 & \multirow{2}{*}{$\begin{array}{l}\text { Wilcox on-Mann- } \\
\text { Whitney }\end{array}$} & \multirow[b]{2}{*}{0.011} \\
\hline & Normal distribution & Normal distribution & & \\
\hline \multirow[t]{2}{*}{ Participant 5} & 0.0269 & $1,728 * 10^{\wedge}-5$ & \multirow{2}{*}{$\begin{array}{l}\text { Wilcox on-Mann- } \\
\text { Whitney }\end{array}$} & \multirow[b]{2}{*}{0.0124} \\
\hline & Normal distribution & Normal distribution & & \\
\hline \multirow[t]{2}{*}{ Participant 6} & 0.0224 & 0.0235 & \multirow{2}{*}{$\begin{array}{l}\text { Wilcox on-Mann- } \\
\text { Whitney }\end{array}$} & \multirow[b]{2}{*}{0.0215} \\
\hline & Normal distribution & Normal distribution & & \\
\hline \multirow[t]{2}{*}{ Participant 7} & 0.0524 & $3,277^{*} 10^{\wedge}-6$ & \multirow{2}{*}{$\begin{array}{l}\text { Wilcoxon-Mann- } \\
\text { Whitney }\end{array}$} & \multirow[b]{2}{*}{0.0254} \\
\hline & Normal distribution & Normal distribution & & \\
\hline \multirow[t]{2}{*}{ Participant 8} & 0.769 & 0.148 & \multirow[b]{2}{*}{ T-Student } & \multirow[b]{2}{*}{0.792} \\
\hline & Normal distribution & Normal distribution & & \\
\hline \multirow[t]{2}{*}{ Participant 9} & 0.0024 & $9.918 * 10^{\wedge}-5$ & \multirow{2}{*}{$\begin{array}{l}\text { Wilcox on-Mann- } \\
\text { Whitney }\end{array}$} & \multirow[b]{2}{*}{0.0724} \\
\hline & Normal & stribution & & \\
\hline \multirow[t]{2}{*}{ Participant 10} & & 0.0001 & \multirow{2}{*}{$\begin{array}{l}\text { Wilcox on-Mann- } \\
\text { Whitney }\end{array}$} & \multirow[b]{2}{*}{0.0580} \\
\hline & Size $<3$ & Normalts & & \\
\hline \multirow[t]{2}{*}{ Participant 11} & 0.009 & $3.265^{\star} 10^{\wedge}-6$ & \multirow{2}{*}{$\begin{array}{l}\text { Wilcox on-Mann- } \\
\text { Whitney }\end{array}$} & \\
\hline & & & & 0.0357 \\
\hline Participant 12 & 0.2343 & 0.0036 & Wilcoxon-Mann- & \\
\hline & Normal distribution & Normal distribution & & 0.0061 \\
\hline Participant 13 & 0.8814 & 0.0036 & Wilcoxon-Mann- & \\
\hline & Normal distribution & Normal distribution & & 0.1989 \\
\hline
\end{tabular}

Figure 5: Analysis of the time spent looking at paintings. 


\section{CONCLUSION AND PERSPECTIVES}

We carried out a pilot study at the Nancy Museum of Fine Arts, the objective of which was to show that there are correlations between the number of fixation points and the fact of appreciating an artwork on the one hand, and between the time spent looking at an artwork and the fact of appreciating it on the other hand. This work is a first step towards modelling the preferences of visitors in a museum based solely on their exploratory and gaze behaviour. We believe that these are promising results towards recommender systems adapted to first-time and anonymous visitors, who do not wish to waste time explicitly communicating their preferences.

Among our perspectives, we want to increase the number of subjects in our study to 100 visitors. In this way, we will increase the statistical power of our tests. We will then deepen our statistical analysis by studying in particular the correlation between the time spent in front of a painting and the number of fixation points to check the degree of attention of the subjects. We will also try to normalize the time spent in front of each painting according to the longest time spent in front of an exhibit for each subject and for all our users combined. In addition, we plan to study the discriminating power of other gaze characteristics such as pupil dilation. The literature shows that there is a correlation between pupil dilation and the person's emotions, especially positive emotions. Finally, in the short term, we planned to design a classification algorithm for predicting visitors' preferences based on their gaze data.

\section{ACKNOWLEDGMENT}

This project has received funding from the European Union's Horizon 2020 research and innovation programme under grant agreement No 693150.

We would also like to thank the Nancy Museum of Fine Arts and the City of Nancy ${ }^{4}$ for allowing us to carry out our study on their premises. Finally, we would like to thank the Institute of Digital Sciences, Management and Cognition (IDMC) for its support.

\section{REFERENCES}

[1] G. Arbelaez Garces, P. Parra, M. Camargo, S. PeÃśarete, and L. Dupont. Understanding museum visitors' experience through an eye-tracking study and a living lab approach. In 22nd ICE/IEEE International Technology Management Conference, Trondhiem, Norway, 2016.

[2] V. Cantoni, L. Merlano, N. Nugrahaningsih, and M. Porta. Eye tracking for cultural heritage: A gaze-controlled system for handless interaction with artworks. In Proceedings of the 17th International Conference on Computer Systems and Technologies 2016, CompSysTech '16, pages 307-314, 2016.

[3] L. Cohen. Culture track 2017 report. https://culturetrack.com/wpcontent/uploads/2017/02/CT2017-Top-Line-Report.pdf, 2017.

[4] O. des publics des ESF. Le profil des visiteurs individuels des musées royaux des beaux-arts de belgique synthèse de lâĂŹenquête de 1996/97. http://www.belspo.be/belspo/pubobs/files/SyntheseannuaireBaugardMRBAB.pdf, 2003.

[5] O. des Publics des Patrimoines. Patrimostat http://www.culture.gouv.fr/Thematiques/Connaissance-despatrimoines/Connaissance-des-publics/Publics-et-patrimoines/PatrimoStat, 2016.

[6] J. H. Falk. An identity-centered approach to understanding museum learning Curator: The Museum fournal, 49(2):151-166, 2006.

[7] C. Z. Felício, C. M. M. de Almeida, G. Alves, F. S. F. Pereira, K. V. R. Paixão, and S. de Amo. Visual perception similarities to improve the quality of user cold start recommendations. In Advances in Artificial Intelligence, pages 96-101, 2016.

[8] K. Kontiza, O. Loboda, L. Deladiennee, S. Castagnos, and Y. Naudet. A museum app to trigger users' reflection. In 2nd Workshop on Mobile Access to Cultural Heritage, MobileCH 2018, Barcelona, Spain, September 03, 2018, 2018.
[9] J. Krukar. Walk, look, remember: The influence of the gallery's spatial layout on human memory for an art exhibition. F. Behavioral Sciences, 4:181-201, 2014.

[10] T. Kuflik. Mobile eye tracking in (cultural heritage) education âĂŞ ideas and research agenda. In 2nd Workshop on Mobile Access to Cultural Heritage, MobileCH 2018, Barcelona, Spain, September 03, 2018, 2018.

[11] T. Kuflik, Z. Boger, and M. Zancanaro. Analysis and Prediction of Museum Visitors' Behavioral Pattern Types. 2012.

[12] T. Kuflik, J. Lanir, E. Dim, A. J. Wecker, M. Corrà, M. Zancanaro, and O. Stock. Indoor positioning: challenges and solutions for indoor cultural heritage sites. In Proceedings of the 16th International Conference on Intelligent User Interfaces, IUI 2011, Palo Alto, CA, USA, February 13-16, 2011, pages 375-378, 2011.

[13] B. M. Information in space is space in information. In Billeder fra det Fjerne/Images from Afar, pages 161-171. 1996.

[14] S. Milekic. Gaze-tracking and museums: Current research and implications. In Museum and the Web (MW 2010), Toronto, Canada, 2010.

[15] M. Mokatren, T. Kuflik, and I. Shimshoni. Using eye-tracking for enhancing the museum visit experience. In International Conference on Advanced Visual Interfaces, AVI 2016, Bari, Italy, fune 07-10, 2016, pages 330-331, 062016.

[16] P. Osche, S. Castagnos, and A. Boyer. Antrs: Recommending lists through a multi-objective ant colony system. In 41st European Conference on Information Retrieval, ECIR 2019, Cologne, Germany, April 14-18, 2019, 2019.

[17] P. Osche, S. Castagnos, A. Napoli, and Y. Naudet. Walk the line: Toward an efficient user model for recommendations in museums. In 11th International Workshop on Semantic and Social Media Adaptation and Personalization, SMAP 2016, Thessaloniki, Greece, October 20-21, 2016, pages 83-88, 2016.

[18] N. C. L. Reed. Understanding visitor happiness in museums. PhD thesis, University of Washington, 2018.

[19] D. Schmitt and O. Aubert. Remind: a method to understand the micro-dynamics of the museum visitors experience. Fournal of Human Mediated Interactions, 17(1):43-70, 2016

[20] R. J. Stein and S. Filippini-Fantoni. Evaluating the practical applications of eye tracking in museums. In Museum and the Web (MW 2012), San Diego, USA, 2012.

[21] E. Verón and M. Levasseur. Ethnographie de l'exposition: l'espace, le corps et le sens. Centre Georges Pompidou, Bibliothèque publique d'information, 1989.

[22] D. S. Wooding, M. D. Mugglestone, K. J. Purdy, and A. G. Gale. Eye movements of large populations: Implementation and performance of an autonomous public eye tracker. Behavior Research Methods, Instruments and Computers, 34(4):509âĂŞ517, 2002.

[23] M. Zancanaro, T. Kuflik, Z. Boger, D. Goren-Bar, and D. Goldwasser. Analyzing museum visitorsâĂŹ behavior patterns. In International Conference on User Modeling (UM2007), pages 238-246, Corfu, Greece, 2007.

\footnotetext{
${ }^{4}$ https://www.nancy.fr/
} 